PRODUCTO DE INVESTIGACIÓN

\section{PONENCIA}

\section{EMPRENDIMIENTO SOCIAL:}

\section{APORTE FUNDAMENTAL AL SECTOR EMPRESARIAL.}

Juan Camilo Vásquez Salazar
UNIVERSIDAD SANTO TOMAS

PERIPLO INTERNACIONAL

BARCELONA 2015-I 


\section{RESUMEN:}

En el siguiente documento se analiza el emprendimiento social dentro del modelo económico y social actual. Para ello, se aborda el concepto mismo de emprendimiento y su rama social, así mismo, se explica esta corriente, se analizan las nuevas tendencias y los retos de la misma, y se finaliza con las conclusiones del tema luego de conectar lo dicho por los autores y los resultados obtenidos después de aplicar el instrumento.

\section{PALABRAS CLAVE:}

Emprendimiento, emprendimiento social, financiación, valor social, agente de cambio.

\section{INTRODUCCION:}

Desde que se dio inicio a las escuelas administrativas ya se estaba hablando del emprendimiento, aunque el mismo es igual de antiguo a la humanidad ya que está inmerso al ser y mucho de lo que vemos en la actualidad es gracias a un emprendedor (el cual podemos definir como una persona que inicia una aventura riesgosa, siguiendo una idea innovadora por la cual lucha y hace lo posible para adquirir los recursos para llevarla a cabo) y es que en semántica la palabra nos dice que emprender es llevar a cabo algo, pero la raíz francesa de la palabra lleva consigo la visión de esfuerzo por lo que el emprendimiento difiere de muchos tipos de negocio en los cuales el riesgo y el esfuerzo son factores decisivos (Castillo,1999), en este orden de ideas el emprendimiento se enlaza con la innovación que podríamos definir como un cambio que introduce novedades, por lo que el emprendedor debe poseer una actitud y aptitud (postura y capacidades) diferentes a un empresario normal, si bien el humano ha sido emprendedor desde siempre por su disposición al cambio lo que ha llevado al mejoramiento de la humanidad, también es de aclarar que se puede desprender el termino emprendimiento de la empresa como tal, ya que se puede ser un emprendedor sin crear una, como es el caso de los intra-emprendedores, los cuales se esfuerzan por mejorar los procesos internos de diferentes escenarios como en el laboral, en el cual su interés seria mejorar las diferentes áreas dentro de una empresa que no les pertenece(Vasquez \& Trujillo Davila, 2008)

Dentro del emprendimiento se pueden encontrar varios casos, desde el emprendimiento familiar en el cual todos unen esfuerzos para sacar su empresa adelante hasta el emprendimiento social, el cual por su impacto a nivel social es de gran potencial,es por ello que en esta ponencia damos gran importancia al concepto y el alcance del mismo ya que este tipo de empresas (actividades) pueden generar una revolución social que es realmente necesaria sobretodo en países en los cuales existen sesgos gigantescos entre los estratos sociales para buscar un bienestar común empezando desde lo local hasta lo global.

El termino Emprendimiento social más conocido como ES por sus siglas tiene su origen en los años 80 y desde ese año hasta la actualidad su participación en el mercado ha venido en aumento, debido a su especialidad y la combinación de lo 
económico con lo sociológico, psicológico y antropológico este tema ha sido presa de críticas y debates acerca de su existencia y su uso particular, ya que se encuentra disonancia entre lo que se espera de un proyecto de emprendimiento y lo que se busca con uno de emprendimiento social por lo cual en el pasado se debatió entre lo que diferenciaba a este de un proyecto social, filantropía, empresa con RSE, cooperativa y en si todo tipo de modelos empresariales con contenido social, lo que termino en una definición del concepto en el cual se nos dice que este tipo de iniciativas no tienen por fin el lucro y buscan alternativas de financiamiento alternativas y modelos organizacionales novedosos para crear valor social.

Todo el tema de emprendimiento se maneja por varios grupos en Barcelona, algunos de índole privada y otros gubernamental (ayuntamiento), pero por el impacto que se ha generado en la ciudad gracias a todos sus servicios enfocados en emprendedores la empresa Barcelona Activa destaca, esta empresa maneja varias líneas de actividad, una de ellas y la que más peso tiene en sus dinamismos es la Iniciativa Emprendedora por medio de la cual brinda un soporte profesional a quienes quieren convertir su idea en una empresa de calidad y con sentido de futuro; cómo podemos ver, en Barcelona Activa buscan generar valor para su ciudad en general lo que se ve reflejado en un impacto social y esto lo hacen respondiendo a las necesidades de sus habitantes ya que para ellos "La iniciativa emprendedora es un bien social, un intangible que resulta motor de actividad, innovación y empleo" (Activa, 2013) lo que se refleja en ser el 19,5\% del PIB español, la 10ma mejor ciudad por producción científica, la segunda Capital de España y muchas más grandes cifras que nos muestran que el esfuerzo del ayuntamiento de Barcelona junto con iniciativas privadas han contribuido al avance de la sociedad en Barcelona por lo cual esta ciudad es ejemplo a seguir para muchas en cuanto a sistema social se refiere; pero además de generar valor social indirectamente para su ciudad por medio de emprendimientos comerciales también tiene un programa de emprendimiento social llamado "Proyectos emprendedores con impacto social" con el cual ofrecen un acompañamiento integral a estas iniciativas aportando una formación y acompañamiento gerencial para la elaboración del plan de empresa y la puesta en marcha del proyecto y a su vez el desarrollo del perfil de emprendedor que se promueve en la empresa junto a retos y beneficios como lo son el premio a la mejor iniciativa de emprendimiento social y financiación a proyectos.

\section{OBJETIVO GENERAL:}

Indagar sobre el impacto real del emprendimiento social en Barcelona y pertinencia del modelo de acompañamiento que tiene el Programa de Emprendimiento Social ofrecido por Barcelona activa con el fin de determinar las posibilidades de que este sea factor clave del sector empresarial que se necesita a largo plazo. 


\section{OBJETIVOS ESPECIFICOS:}

- Observar el avance de la empresa social dentro del mercado en Barcelona con el fin de analizar su viabilidad y alcance a futuro.

- Identificar los pros y contras del modelo de emprendimiento social actual con el fin de visualizar que tanto se puede potenciar el modelo para aumentar la cobertura de su impacto.

- Observar si en las iniciativas de Barcelona activa realmente se incentiva a lo social para determinar si el programa cuenta con lo necesario para atraer a los emprendedores de Barcelona.

\section{REVISIÓN LITERATURA:}

A continuación se presentan 5 artículos los cuales nos muestran y explican el concepto de Emprendimiento social desde varias perspectivas y la aplicación del mismo en diferentes contextos a la vez que su lugar dentro de la economía actual y la visión que se tiene por algunos sectores sobre su importancia en el futuro.

\subsection{ARTICULO:}

El emprendimiento social: Estructura organizativa, retos y perspectiva de futuro.

Marta Curto Grau

Cuadernos de la Cátedra "la Caixa" de Responsabilidad

Social de la Empresa y Gobierno Corporativo

El termino de ES se ha venido usando desde los años 80 `s y su uso ha crecido desde ese momento ya que las campañas oficiales no impactan en la sociedad, para al ES lo importante debe ser genera el proceso de generación de valor social y funcionamiento interno de las empresas.

El principal reto del ES es la financiación ya que su objetivo no es rentable a largo plazo ,por lo que no es atractivos para inversionistas, debido a esto la Unión Europea ha generado propuestas de financiación para este tipo de empresas la cual se caracteriza por:

- Marca propia para fondos Europeos de emprendimiento social- Estos fondos tiene un destino del más de su $70 \%$ a lo social.

- Objetivo: facilitar la creación de este tipo de fondos y la capacitación de inversionistas.

- AL ser una inversión de riesgo elevada se tenía el acceso restringido a inversionistas profesionales peor esto ha ido desapareciendo con el tiempo.

1.1.1 Organización y gobernanza: Los modelos organizacionales para él ES se enfocan en lassiguientes cuestiones:

- Red apropiada para generar valor social, enfocado en llegar al grupo beneficiario (asociaciones) (toda la cadena de valor). 
- Correcto aprovechadito de los recursos estratégicos: promover la significativas haciendo uso de las características geográficas. Demográficas y de más.

- Gestión de las relaciones entre la organización y los beneficiarios- crear un estrecho vinculo con los stakeholders.

\subsubsection{FASES DEL EMPRENDIMIENTO SOCIAL:}

Para producir un emprendimiento social es importante responder todas las preguntas que se plantean en estas dos fases:

\subsubsection{FASE DE DISEÑO: preguntas clave}

- ¿Qué función desarrollaras en tu propia empresa?

- ¿Qué servicios obtendrás de tus proveedores?

- ¿Qué servicios/soporte te prestaran tus socios?

\subsubsection{FASE DE PRÁCTICA:}

- ¿Quién se beneficiara (o podría beneficiarse potencialmente) de tu empresa?

- ¿Sería apropiado (y factible) cobrar una tasa por el beneficio brindado?

- En caso de cobrar ¿Cuál sería le importe adecuado?

Estas dos últimas preguntas son muy importantes para el emprendedor, y debe analizar muy bien qué decisión tomar, ya que hay emprendimientos sociales sin ánimo de lucro, con ánimo de lucro e híbridos.

1.1.2 Gobernanza de la empresa social: Esto es responsabilidad de la junta directiva y debe estar enfocada primordialmente a los stakeholders sin olvidar a los accionistas, este tipo de hibridación es a causa de evitar la falta de profesionalismo en las empresas y generar así una sostenibilidad.

Ya que lo ideal es que las empresas pretendan no depender de donaciones y consolidarse financieramente para ser atractivas a los inversionistas.

1.1.3 Reto acceso al capital: Como ya habíamos nombrado anteriormente el acceso al capital es el reto más grande la que se enfrenta un emprendedor ya que se presenta que hay mucha competencia, los inversores no quieren correr riesgos y el gobierno no da el apoyo suficiente, por esto mismos para captar fondos el emprendedor debe:

1. Pensar en el resultado deseado.

2. Considerar aquellas formas en las que necesite menso recursos.

3. Tener presente la incertidumbre que rodea el proyecto. 
Así ya se puede pensar en que rama de Financiamiento se erigirá, de estas podemos encontrar ahora mismo los siguientes tipos:

- Subvenciones- donaciones.

- Subvenciones recuperables (préstamos sin interés)

- Prestamos con interés por debajo de la media, en la media, por encima de la media.

Pero acceder a estas no es tan fácil, para las empresas con ánimo de lucro existe un amplio abanico, a diferencia de las constituidas sin ánimo de lucro ya que a estas se les reducen las opciones

Una de las financiadoras de proyectos de este tipo más importantes es ASHOKA quienes además de hacer los préstamos hacen un seguimiento y acompañamiento a los emprendedores de manera gratuita y para toda la vida, pero acceder a esto no es tan fácil ellos buscan un perfil especial el cual ellos definen en 5 ítems:

- Idea nueva.

- Candidato creativo.

- Candidato emprendedor.

- Impacto- cambiar las cosas.

- Candidato con sentido ético.

También es importante recordar que las donaciones y subvenciones siempre tiene un costo, así sea el de desgaste administrativo, e inherentemente el costo de dependencia el cual es el que generalmente aleja a los inversionistas.

Este articulo concluye en que él ES no tiene fracasos a diferencia de otros modelo de negocio, en el ES lo que habrán serán frenos y obstáculos y ahí el reto del emprendedor; además de que es necesaria manos investigación para poder perfeccionar el concepto de ES ampliarlo y adaptarlo a las necesidades de la actualidad.

\subsection{ARTICULO:}

Revisión conceptual empresas sociales.

Alcaldía de Medellín Comfama Ciudad e-Líder en emprendimiento

Este artículo nos habla de Colombia dentro del Emprendimiento social y nos muestra los ejemplos y avances en el mundo, tomaron como fuente entrevistas a expertos con experiencia en el tema e información web, artículos y libros.

ELEMENTOS CLAVES ES:

- Objetivo social.

- Innovación trasformadora.

- Modelo de negocios sostenible. 
EI ES funciona mejor y es más necesario en economías en desarrollo en las cuales la acción del estado es ineficaz.

Hay que tener claro que no es lo mismo hablar de emprendimiento social y Responsabilidad social empresarial o activismo social, el aporte del emprendimiento social es muy diferente; El aporte general de este tipo de emprendimiento es el contribuir en el desarrollo de la humanidad y para esto se generan aportes específicos como lo son:

- Generar empleo y desarrollar población vulnerable.

- Mejora la calidad de servicios sociales.

- Fomenta prácticas éticas n el mercado.

- Sensibiliza nuevos empresarios que quieran hace runa diferencia en la sociedad.

Es por esto que aportar de rebote a la sociedad no convierte en una empresa social, es necesario que los objetivos de la empresa estén dirigidos al crear valor social; en muchas ocasiones se suelen confundir los conceptos debido a que en cuestión teórica conceptual falta mucho debido a las diferentes posturas, corrientes y conceptos que se han vendió generando sobre él ES.

Un emprendedor y un Emprendedor social, son iguales exceptuando por su motivación y convicción, ya que los segundos no tienen como prioridad el beneficio económico.

1.2.1 Corporación Mondragon: Este es un grupo Vasco extendido por toda España, es el 7 mo grupo de empresas mas importante de toda España y el número 1 del país vasco, este está conformado por 256 empresas y aportan 1 peso de cada 100 que les quedan disponibles por medio de su cooperativa a los emprendimientos sociales.

Dentro del artículo nos hacen alusión a que no es lo mismo una Cooperativa a una empresa social, ya que la cooperativa busca maximizar utilidades monetarias, estas no tienen como objetivo último el impacto social, ni miden sus actividades de esta forma.

1.2.2 CGM: Modelo de socio trabajadores italiano que se enfoca en las personas con desventajas para lograr su promoción y desarrollo, su objetivo es el de promover el desarrollo de la corporación social y dicen que las empresas sociales difieren de las demás empresas por el lugar en el mercado.

1.2.3 Empresas sociales actuales: Este tipo de empresas miden sus utilidades en beneficio social y no en TIR, un ejemplo de estas es:

Grameen Danone: producen yogures de alta calidad para personas pobres, al vender sus productos a un bajo precio no alcanzan utilidades significativas para sus accionistas, pero generan un impacto en las comunidades de escasos recursos y son sostenibles financieramente. 
1.2.4 ASHOKA: Brindan apoyo a emprendedores sociales con la premisa de que "todo el mundo puede cambiar el mundo", buscan desarrollar las competencias de los emprendedores ya que la base de la pirámide para ellos son las oportunidades de negocio, se incentivan los negocios inclusivos los cuales tienen como característica que son rentables económica, social y ecológicamente, y su fin es el mejorar la calidad de vida de las personas de escasos recursos a través del estimulo de sus participación en la cadena de valor de la empresa guiándose por la teoría del valor compartido en la cual hay un circulo viciosos entre la empresa y la sociedad, así que se debe colaborar entre las partes, aunque a esta mirada sele critica mucho por su falta de visión a largo plazo.

1.2.5 LEED: Este es un programa de la OCDE, consiste en un foro de gobiernos en el cual se busca que se compartan ideas, intenciones y experiencias que busquen dar solución a problemas comunes.

1.2.6 En Colombia: Ios emprendedores sociales colombianos han tratado de tomar posturas internacionales por medio de benchmarking, y se evidencia que en el país las instituciones universitarias son pioneras en el tema.

El gran problema en Colombia es que seguimos viendo este tipo de empresas como empresas filantrópicas de aporte a corto plazo por medio de caridad y limosnas

\subsection{ARTICULO:}

El perfil del emprendedor social del estudiantado de los grados de educación social, pedagógica y trabajo social en la Universidad de Barcelona.

Virginia Ferrer Cerveró Olga E. Cabrera Santacana Rosa María AlegreAlejandra Montané López Carlos Sánchez Valverde Eneida Alaiz Chueca Reire revista d'innovació i recerca en educación-Universitat de Barcelona

Este artículo se realiza con base al interés que se tiene en una economía sostenible y con valores sociales, por lo que vemos que las universidades deben acomodarse al mercado y por ello en muchas se ha ido incluyendo la Emprendeduria Social ya que estas han analizado e identificado las necesidades formativas del emprendedor de perfil social y la necesidad de estos en el mercado. Investigación: "Análisis y configuración del perfil del emprendedor social de los grados de educación social, pedagogía y trabajo social: trasferencia y movilización de conocimientos, habilidades y perspectivas." (Virginia Ferrer-Cerveró, 2014)

Objetivo General: Re direccionar la pedagogía según contexto actual:

Objetivos específicos: 
- Identificar necesidades formativas en relación con el emprendimiento social.

- Formar perfiles universitarios creativos e innovadores.

- Mejorar la actitud del docente.

Europa apuesta por la empresa social, el crecimiento sostenible e incluso innovación social; Con esta investigación se evalúan el perfil y las buenas prácticas del emprendedor social.

En términos de Trasferencia social del conocimiento para el emprendimiento universitario, el concepto de ES es muy rígido económico y administrativo, siendo que debería contener un amplio contenido humano-social y cultural, ya que la trasferencia de conocimiento en este campo es muy lenta debido a que es difícil ajustar el tema a un marco teórico de fundamentación pedagógica; ahora mismo la transferencia de conocimiento es ahora mismo una responsabilidad universitaria ( crear grupos de investigación ya que casi ninguna tiene especialidad humanista.

Debido a esto la Universidad de Barcelona tiene como opción de grado el Emprendimiento social, en el cual aceptan cualquier tipo de objeto para estas empresas.

La ES se define según la UB en dos partes, el aporte de cambio e impacto social; y su objetivo es crear vínculos entre empresas y Universidades ya que esto es una necesidad inminente para el mundo de la pedagogía; El apoyo a los emprendimiento sociales ha venido incrementando, en el mundo ya hay varios grupos en varios países, en el marco de la Unión Europea se han generado varias iniciativas enfocadas en este tema.

En este artículo se habla del impacto del emprendimiento social en 4 ítems nombrados a continuación:

- Problemas sociales.

- Problemas eco ambientales.

- Problemas culturales.

- Problemas educativos.

La metodología que se utilizo para recoger toda esta información fue la de realizar un cuestionario, el cual en su primera parte buscaba obtener datos generales de la población de estudiantes encuestados así como elementos del perfil emprendedor de este alumnado, y en su segunda aparte era sobre la percepción y conocimiento sobre la emprendeduria social; sumado a este cuestionario también se utilizo la observación, para identificar las buenas prácticas y como se realiza la selección poblacional (segmentación) de los proyectos de ES.

Como resultados se obtuvo que se tiene un buen conocimiento y disposición por parte de los alumnos a realizar empresas sociales debido al impacto que estas pueden llegar a tener en la comunidad. 


\subsection{ARTICULO:}

\section{Emprendimiento social revisión de literatura.}

Doctor Alexander Guzmán Vásquez Doctora María Andrea Trujillo Dávila Estudios Gerenciales Vol. 24

El emprendimiento se ha estudiado desde diversas disciplinas las cuales se podrían dividir en dos partes, las económicas y las sociológicas, psicológicas y antropológicas.

Al definir el emprendimiento se habla de que este es el descubrir oportunidades rentables, pero aquí hacen énfasis a que las oportunidades no deben descubrirse, deben construirse, es por esta definición que es difícil hablar de teorías del emprendimiento social, ya que no hay coherencia entre los anterior mente dicho con el tratar de abordar problemas sociales, lo que es el fin del emprendimiento social.

Pero aun así, hay que tener claridad que el emprendimiento social coexiste con el emprendimiento comercial, ambos generan valor, uno social y el otro económico, y su diferencia principal está en sus motivaciones y la forma en la que miden su impacto/beneficio.

1.4.1 Valor social sostenible: Dar una voz para resolver problemas sociales, algunos muy poco tratados como la planificación, una verdadera e integra educación sexual, discapacidades mentales, el cigarrillo, y en si muchos problemas que rodena a adolescentes y niños, quienes no son foco de atención en la mayoría de proyectos y romper las barreras las cuales son:

- Sociales.

- Geográficas.

- Financieras.

- Culturales.

Todo esto tendrá un impacto en el modelo social, acabando con el capitalismo salvaje, por el cual la derecha lacera a la sociedad, ya que para países emergentes es degran importancia él ES privado pero por el modelo socioeconómico no es impulsado, en consecuencia de eso, se debería replantear los impuestos y aumentar e incentivar el ES para que así se aumenten las posibilidades de ser exitosos localmente y luego expandir ese impacto a nivel global. 


\title{
1.5 ARTICULO:
}

\section{La empresa social: Revisión de conceptos y modelo para el análisis organizativo.}

\author{
Ramón Fiscal \\ Ana Molano Romero \\ Carlos MataixAldenueva \\ Miguel Palacios fernandez \\ Revista Española del tercer sector
}

La empresa social es aquella que mediante su actividad económica habitual genera valor social inclusivo, el cual promueve al desarrollo de la humanidad, este tipo de empresas ganan importancia en un momento como el actual en el cual el modelo económico de libre mercado ha ido generando grandes diferencias entre los niveles de vida entre países y a nivel local la distancia abismal que existe entre el más pobre y el más rico, bien es cierto que la globalización ha permitido grandes avances y ha generado un aumento en el consumo y la oferta de bines y servicios pero también ha traído consigo la exclusión social; la exclusión social es mucho más que la pobreza, también abarca temas como las condiciones laborales, el acceso a la educación, vivienda, salud, estructura de familia, y es que hay que ser consientes q esta exclusión social nos afecta a todos, por esto es que las empresas deben estar más comprometidas y dejar a un lado la filantropía y el cumplimiento de normas de RSE para hacer marketing.

El movimiento del sector social es muy lento a diferencia del de la empresa tradicional, lo que genera que hayan quienes piensen que este sector no aporta, pero en los últimos años hemos visto como el modelo económico que se ha basado en un crecimiento rápido por la generación de beneficios económicos a corto plazo ha entrado en crisis por todo el mundo poniendo en evidencia la insostenibilidad del actual modelo ya que no ha podido promover un desarrollo sostenible en el ámbito económico, social y ambiental, es por esto que Europa dirige sus esfuerzos a la economía social en la cual se le da más valor a la persona y no la capital ni la tierra y en especial a las empresas con vocación social compatible con su actividad económica.

\section{MÉTODO:}

Estudio de caso exploratorio donde implemente el instrumento "entrevista semiestructurada" seleccione este tipo de entrevista a fin deobtener más matices de respuesta, lo que me permite ir entrelazando ideas, guiar y estirar temas importantes y con esto llegar a conclusiones más completas, sin dar oportunidad al entrevistado de salirse del guion (Jiménez, 2012), el instrumento está diseñado para ser aplicado a profesionales en el tema de Emprendimiento dentro de la Administración de empresas y que tengan conocimiento sobre las actividades que se llevan a cabo en la actualidad tanto por Barcelona Activa como por las demás empresas dedicadas a impulsar este tipo de iniciativas a fin de tener una visión 
objetiva, completa y realista del tema; las personas a quienes se les realizo la entrevista se relacionan a continuación.

ENTREVISTADO 1: GABRIEL IZARD /Director de Revista EconomíaCAT, Coordinador Master of Executive Business Management UAB. Delegado AxiconSpain, Profesor Marketing y Distribución.

ENTREVISTADO 2: XAVIER VERGE MESTRE /Subdirector de la Escuela de Ingeniería UAB, Profesor en Ciencias Económicas y Empresariales, sistemas de información, MBA UAB.

ENTREVISTADO 3: DANIEL BLABIA / Coordinador Máster Universitario en Gestión de Empresas Hoteleras y Máster Citius, profesor de sistemas de información y del business game hotelero al Departamento de Empresa de la UAB y EUTDH.

\section{INSTRUMENTO IMPLEMENTADO: (EN ANEXO)}

\section{RESULTADOS:}

\section{¿Cómo definiria usted el emprendimiento social?}

1. Es la iniciativa empresarial enfocada a mejoras de la sociedad.

2. El emprendimiento social es un tipo de emprendimiento por lo tanto hay una parte de emprendeduria igual que cualquier otra, pero se distingue en que el objetivo no tiene por qué ser la maximización de beneficios, el objetivo principal puede ser ayudar a otras personas o bien incluir socialmente, y cualquier otro objetivo que tenga un retorno social, ahora, debe ser sostenible

3. El emprendimiento que tiene un beneficiario que es la sociedad en general.

\section{¿Para usted que diferencia él ES del EC?}

1. El enfoque hacia donde diriges la actividad.

2. Justamente el objetivo que persiguen y a partir de aquí de desencadenan una seria de condicionantes tanto las relaciones entre los stakeholders de cualquier tipo.

3. Me gustaría pensar que es gente joven que ha vivido una época dura, que ve que el fin de unos recursos se está acercando, que el modelo macroeconómico se está desgastando y que aunque sea por su propia supervivencia debe encontrar un modelo alternativo y les toca a ustedes hacer ese ejercicio.

\section{¿Para usted cual es el perfil de un Emprendedor social/ agente de cambio?}

1. Ya para emprender debes tener una cultura del emprendimiento, además si emprendes socialmente tienes que tener un enfoque hacia el tema social.

2. Pues los que yo conozco, pues no tengo un perfil determinado, de hecho cualquiera puede ser un emprendedor social, pero suele ser gente preocupada por los valores sociales, gente con inquietudes y ganas de cambiar el mundo tanto hombres como mujeres no hay diferencia, que tienen fundamentalmente 
una conciencia social importante, y una preocupación por las desigualdades y preocupación por injusticias sociales de todo tipo.

3. Me gustaría pensar que es gente joven que ha vivido una época dura, que ve que el fin de unos recursos se está acercando, que el modelo macroeconómico se está desgastando y que aunque sea por su propia supervivencia debe encontrar un modelo alternativo y les toca a ustedes hacer ese ejercicio.

\section{¿Cómo puede usted evidenciar el impacto del ES en la actualidad?}

1. Bueno, pues con muchas iniciativas, yo no conozco ningún indicador que mida esto actualmente pero sí que hay iniciativas así como la que habéis visto en el ejemplo de emprendimiento para gente con disminución intelectual en la empresa la Fageda de yogures y lácteos.

2. Hay un fuerte avance en todo lo que es el emprendimiento social de hecho en la última elección de alcalde, la alcaldesa actual responde a señalamientos mucho más preocupados por el impacto social de las acciones políticas, ¿tiene que ver con emprendimiento social? Bueno, se acerca un poco a esta vista, no obstante en gobiernos anteriores que eran más liberales para entendernos, seguían apostando fuertemente por estos aspectos, es mas incluso también grandes corporaciones como "La Caixa" dentro de su programa social, da mucha importancia a lo que es emprendimiento social, o el ayuntamiento de Barcelona también incluso antes de estas elecciones también disponía de bastante impulso a este tipo de emprendimientos

3. En mi caso yo estoy en contacto con mucha gente que lanza proyectos nuevos, en forma de propuestas $p$ empresas reales, start ups y cada vez me doy cuenta que el objetivo último de hacerme rico de ganar mucho dinero en 'poco tiempo, va desapareciendo, la gente cada vez asumen mientras tenga el dinero para poder vivir bien ese no explotar al máximo los recursos, las maquinas todo, yo creo que es ella es un retorno social.

\section{¿Qué ES rescata usted dentro de los que conoce por su modelo innovador?}

1. La que comentaba ahora mismo es muy buena (La Fageda).

2. La Fageda, es una fábrica de yogures que ya te pasare información sobre la misma.

3. Bueno, yo creo que cada vez nos encontramos mas con empresas, yo creo que las que más han hecho daño son las que ahora son primeras en hacer proyectos, por eso veo proyectos interesantes de bancas, de empresas químicas, de petroleras es decir que empresas que sobre ellos ya tenían la marca la señal de ser los que a nivel medio ambiental o a nivel de explotación de zonas pobres del planeta habían extirpado y dañado.

\section{¿Qué mejoraría o añadiría usted al modelo de ES que se ve en la actualidad?}

1. Hay un tema ligado con el tema de enfoque social, que es un aspecto que se llama economía de bien común que también va ligado con la cuestión empresarial y es que no solamente es medir las actividades empresariales por los beneficios o por los ingresos, sino medirlo también por el impacto social que tiene, hay iniciativas ahora mismo como por ejemplo una ONG inglesa 
tratando de implementar un indicador que mida como un termómetro a través de datos que están publicados en las memorias de las empresas que puede medir el impacto social de su empresa, impacto que puede ser por contaminación, por empleo y por otros varios.

2. Más difusión y más ambición.

3. A mí me gustaría que la empresa que tiene un objetivo social que tiene un objetivo... aa hay una cosa que me encuentro en muchas ocasiones, que es que parece que la gente que tiene este tipo de emprendedurias esta menos formada que aquellos que su objetivo es el de hacerse millonario, no me gustaría que eso fuese así, me gustaría que hubiera formación específica para esta gente, para este tipo de empresas que trabajan para este tipo de proyectos, que la medida de éxito no sea solo el estado de resultados, si no que sean otras, y hay que formar a la gente en estas otras, este tipo de gestión; yo creo que la gestión de este tipo de empresas es realmente diferente a las que estudiamos en las facultades, y pues si que habría que formar mejor, para que no suceda esto de gente con mucha voluntad, muchas ganas pero que le falte las herramientas reales para gestionar.

\section{¿Cree usted que el modelo de Empresa social puede ser un trasformador del modelo de mercado y sistema socio económico actual? ¿Por qué?}

1. Bueno, este es un tema más ideológico que económico, respeto la ideología de cualquiera, hay gente que critica al mercado y hay gente que lo apoya, yo no me iré por una cosa ni por otra, lo que si te digo es que el mercado tiene unas funciones y la visión social de la actividad económica puede estar también de acuerdo con estos puntos, si lo dejamos todo al mercado pues seguro que la parte social no va a mejorar, pero si se le ponen incentivos de tipo social a las empresas en el mercado seguramente y que sean catalogadas por la ley, por ejemplo hay industrias como la salud, sanidad, suministros, agua etc. que tienen que tener un componente social evidente, por esto es que se deben crear unas políticas que sean adecuadas para que los países funcionen mejor en este ámbito.

2. Puede, pero es complejo, por que el modelo capitalista tradicional está muy implementado y muy asentado y muy arraigado según los sectores y en algunos sectores es terriblemente eficiente por lo cual es difícil de desplazar, no obstante hay otros sectores que sí , que si tiene su oportunidad pero hace mucha más voluntad de individuos más emprendedores

3. Me gustaría que lo que ha empezado como una tabla de salvación para la gente joven, como una salida, la única salida que queda, al final entre todos no lo acabemos creyendo y entre todos cambiemos este proceso y si supongo $\mathrm{q}$ si al igual que la revolución industria cambio una sociedad, y una manera de gestionar el mercado, yo creo que la falta de recursos que yo creo que es el gran auge, falta de recursos, falta de objetivos vitales etc., yo creo que puede hacer cambiar la sociedad, creo que se ha demostrado. 
¿Considera usted que el impacto del ES puede expandirse a todos los niveles sociales? ¿Por qué?

1. $\mathrm{Si}$, puede extenderse a cualquier ámbito, evidentemente se enfoca, a personas pobres, personas analfabetas, con exclusión social, inmigrantes, lo que sea pero también la idea es que se equilibre la balanza entre ricos y pobres para que las clases medias no desaparezcan, para que las clases de bienestar, que están en este momento en crisis pues no desaparezcan.

2. Si en realidad hay muchas, aunque principalmente la mayoría se centran a temas de integración.

3. Se empieza apagando los incendios más grandes que tiene, después se irán apagando los incendios menores, por eso creo que se inicia con marginalidades, porque si, necesidades sociales tenemos todos, de mejorar nuestra calidad de vida, así sea personal, de nuestro entorno, yo siempre pongo el ejemplo, en donde está ubicada la universidad es una de las poblaciones con la renta per capital de toda España, es la población en donde se venden más antidepresivos en toda España, ahí está la relación entre las personas que tienen más de todo pero necesitan antidepresivos, es decir necesidades hay muchas y yo creo que se irán solucionando con el tiempo una por una.

\section{¿Cuál cree usted debe ser el objetivo final de los emprendimientos sociales} a futuro aparte del generar valor social?

1. El respeto al mundo, quiero decir queremos un mundo sostenible en el futuro, que no se apague, la sostenibilidad en el sentido más amplio, ecológico, energético, de recursos, es lo que mejor se puede hacer, y el mercado por sí solo no lo hace, así que debemos actuar para que tengamos luz nosotros nuestros hijos y sus nietos.

2. Buscar que sean más sostenibles y que sean más grandes.

3. Yo creo a lo social es la sostenibilidad, es decir ahora alguien te explica un negocio y piensas que ese negocio acabara muriendo, que otra empresa la comprara; desaparecer este concepto de empresa que nace y alcabor de 10, 15 años se quema, vente ,acaba muriendo, renace en otra, yo creo que aquí hablamos de proyectos que deben ser trasnacionales, que tienen que ser vitalicios, bueno yo creo cambiar mucho el formato, tienen que ser una cosa vitalicia, ser servicios que la sociedad presta a la sociedad, y no hace falta cambiar de nombre ni de marca, si no que exista una buena experiencia en Colombia en Chile, en Bélgica, tiene que ser una buena experiencia para todos en todos los países y estará colgada en la nube y tendrá un sistema de financiamiento y lo tomara la gente joven, o la gente mayor y pues entonces yo creo que es por ahí.

\section{CONCLUSIONES:}

Después de conocer Barcelona Activa, el centro de Investigación de la UAB, escuchar sobre iniciativas existentes, leer artículos relacionados con emprendimiento con enfoque general y enfocados en Barcelona escuchar las respuestas en la entrevista realizada, conocer una emprendedora de Barcelona y 
escuchar su historia, y ver como se mueve el mercado y en general la vida en Barcelona, podemos ver que se tiene en esta ciudad muy presente y que se le da la importancia necesaria a todo lo relacionado con emprendimiento, por ende se tiene muy claro el concepto y sus objetivos, todo esto repercute en que las entidades encargadas de la formación de los ciudadanos como los son las Universidades y demás centros de enseñanza, les hagan a estos ser conscientes de la importancia y del buen uso que se le puede dar al emprendimiento, estas instituciones impulsan el emprendimiento y lo utilizan como motor para el desarrollo desde el ámbito local hasta el mundial, es importante ver cómo se maneja la RSU de forma que genera un impacto social indirecto que es mucho más grande que el que podrían generar directamente pero sin hacer participes las ideas de sus alumnos(Vallaeys,2008); los alumnos al tener una guía en temas del emprendimiento y ver que se dirige esta a generar valor para Barcelona comienzan a adquirir una conciencia y perfil de aptitudes y actitudes que los convierten en emprendedores agentes que cambio con las herramientas necesarias para en un futuro guiar las actividades de toda una ciudad con un enfoque de valor social sostenible, si en todas las disciplinas se creara conciencia sobre la importancia de generar valor social es seguro que la financiación no sería un reto para el emprendedor, ya que como se evidenciaen Barcelona los ayuntamientos (alcaldías) de cada ciudad dirigirían parte de sus esfuerzos a esta clase de iniciativas que bien generan el valor que aumentara la calidad de vida de todos.

Tomando como punto de referencia el método y los resultados de este frente a los objetivos que se plantean desde un inicio podemos concluir que: en Barcelona se tiene una idea colectiva sobre el termino ES el cual es: la iniciativa que busca mejoras en la sociedad a base de un retorno social enfocado a la comunidad, que lo que diferencia al ES del EC es hacia donde se dirige la actividad en cuanto a su retorno, que no se tiene claro el perfil de un emprendedor social, esto puede bien ser debido a que este no existe ya que diferentes tipos de persona pueden serlo, que hace falta un indicador de utilidad social aparte de la conciencia de la comunidad para poder medir el impacto, que existen insignias dentro del emprendimiento social en Barcelona que son apoyadas por el ayuntamiento y por el programa de de BA (La fageda), que al modelo de ES de BA le hace falta más difusión, educar mejor a sus emprendedores para que sean profesionales en le tema y así inculcarles mas ambición en sus proyectos, que dentro de las posturas de protección y boicot al mercado actual ambas apoyan al emprendimiento social desde diferentes vistas, que el emprendimiento social puede terminar beneficiando a la humanidad y no solo a los sectores marginados, pero que como lo Dijo Daniel Blabia "Es importante empezar apagando los incendios más grandes" (Blabia, 2015), y que lo que le hace falta al emprendimiento es un enfoque más sostenible en el tiempo así su aporte social será constante y duradero.

Es por esto que el emprendimiento social puede llegar a ser el trasformador del modelo de libre mercado actual, pero esto no es nada fácil, este es un trabajo al que estamos llamados todos, debemos crear conciencia sobre la importancia de que las empresas generen valor social para la comunidad y no solo valor 
comercial para los accionistas, lo que será difícil ya que para algunos el modelo capitalista funciona de manera optima ya que les genera unos beneficios monetarios, pero hay que ser consientes que el generar valor social ya bien sea mejorando la calidad de vida de los marginados o con temas relacionados con la escases de recursos, terminara siendo mejor inversión y no solo para el individuo si no para toda la comunidad ya que con esto se solucionarían muchas problemáticas y el desarrollo de la humanidad se aceleraría.

\section{Bibliografía}

Castillo, A. (1999). Estado del arte en la enseñanza del emprendimiento. Emprendedores como creadores de riqueza y desarrollo regional.

Boisier, S. (2001). Sociedad del conocimiento, conocimiento social y gestión territorial. Interações, 2(3), 9-28.

Activa, B. (s.f.). (2013) Barcelona Activa. Recuperado el 25 de 5 de 2015, de http://www.barcelonactiva.cat/barcelonactiva/es/

Grau, M. C. (2012). EL EMPRENDIMIENTO. Cuadernos de la Cátedra "la caixa" de responsabilidad social de la empresa y el gobierno corporativo, 24.

Sennett, R. (2000). La corrosión del carácter. Las consecuencias personales del trabajo en el nuevo capitalismo. Anagrama, Barcelona.

medellin, A. d., \& Comfama. (2012). Revisión conceptual:Empresas Sociales. Ciudad e , 36.

Roa, N. A., \& Sierra Morales, O. A. (2014). Responsabilidad social universitaria y emprendimiento. Gestión \& Sociedad, 18.

Vasquez, A. G., \& Trujillo Davila, M. A. (2008). Emprendieminto Social, revisisón de literatura. Estudios Gerenciales , 21.

Fisac Garcia, R., Moreno Romero, A., Mataix Aldeanueva, C., \& Palacios Fernández, M. (2011). La empresa social: revisión de conceptos y modelo para el análisis organizativo. Revista Española del Tercer Sector, 41-66.

Virginia Ferrer-Cerveró, O. E.-S.-M.-B.-C.-V.-E.-C. (2014). El perfil del emprendedor social del estudiantado de los Grados de Educación Social,. REIRE, Revista d'Innovació i Recerca en Educació , 19.

Jiménez, I. V. (2012). La entrevista en la investigación cualitativa: nuevas tendencias y retos. Calidad en la Educación Superior, 3(1), 119-139.

Trujillo Dávila, M. A., \& Guzmán Vásquez, A. (2008). Intraemprendimiento: Una revisión al constructo teórico, sus implicaciones y agenda de investigación futura. Cuadernos de administración, 21(35), 37-63. 
Matiz, F. J. (2013). Investigación en emprendimiento, un reto para la construcción de conocimiento. Revista EAN, (66), 169-182.

Correa, C. I. O. (2010). La dimensión humana del emprendimiento. Revista Ciencias Estratégicas, 7-9.

Barea, I. (1990). Concepto y agentes de la Economica Social.

Moreno Fernández, L., \& Pérez Yruela, M. (1992). Política social y estado del bienestar. Ministerio de Trabajo y Asuntos Sociales.

Vallaeys, F. (2008). ¿ Qué es la responsabilidad social universitaria. Palestra, Pontificia Universidad Católica del Perú.

Sans Guañabens Marc, Comunicación personal, (8 de Junio de 2015)

Verge Xavier, Comunicación personal, (9 de Junio de 2015).

BlabiaDaniel, Comunicación personal, (10 de Junio de 2015).

IzardGabriel, Comunicación personal, (11 de Junio de 2015).

\author{
ANEXO \\ EMPRENDIMIENTO SOCIAL: \\ APORTE FUNDAMENTAL AL SECTOR EMPRESARIAL. \\ - JUAN CAMILO VÁSQUEZ SALAZAR
}

INSTRUMENTO IMPLEMENTADO: Entrevista Semi-estructurada con expertos.

ENTREVISTADO: NOMBRE

\title{
PARTE 1: GENERALIDADES DEL EMPRENDIMIENTO SOCIAL
}

1. ¿Cómo definiría usted el emprendimiento social?

2. ¿Para usted que diferencia él ES del EC?

3. ¿Para usted cual es el perfil de un Emprendedor social/ agente de cambio?

\section{PARTE 2: ACTUALIDAD EN EL MERCADO E IMPACTO REAL}


1. ¿Cómo puede usted evidenciar el impacto del ES en la actualidad?

2. ¿Qué ES rescata usted dentro de los que conoce por su modelo innovador?

3. ¿Qué mejoraría o añadiría usted al modelo de ES que se ve en la actualidad?

\title{
PARTE 3: FUTURO DEL ES E IMPACTO A LOGRAR EN LA SOCIEDAD
}

1. ¿Cree usted que el modelo de Empresa social puede ser un trasformador del modelo de mercado y sistema socio económico actual? ¿Por qué?

2. ¿Considera usted que el impacto del ES puede expandirse a todos los niveles sociales? ¿Por qué?

3. ¿Cuál cree usted debe ser el objetivo final de los emprendimientos sociales a futuro, aparte del generar valor social?

\author{
ANEXO DOS \\ AUDIOS DEL INSTRUMENTO SIENDO IMPLEMENTADO
}

